\title{
School principal self-efficacy for instructional leadership: relations with engagement, emotional exhaustion and motivation to quit
}

\section{Cecilie Skaalvik ${ }^{1}$}

Received: 9 October 2018 / Accepted: 31 January 2020 / Published online: 19 February 2020

(c) The Author(s) 2020

\begin{abstract}
The current study explored relations between principal self-efficacy for instructional leadership, emotional exhaustion, engagement, and motivation to quit the work as a principal. Participants in the study were 340 principals in elementary school and high school in five randomly selected counties in Norway. The theoretical frameworks for the study were self-efficacy theory and theoretical perspectives on instructional leadership. A new 15-item "Norwegian self-efficacy for instructional leadership scale" consisting of five subscales was developed and tested by means of confirmatory factor analyses. Both a model defining five correlated primary factors (Model 1) and a model defining a single second order factor (Model 2) had good fit to the data. SEM analysis revealed that self-efficacy for instructional leadership was negatively related to emotional exhaustion and positively related to engagement, indicating good criterion validity of the scale. Self-efficacy was also negatively related to motivation to quit. This relation was indirect and mediated through both emotional exhaustion and engagement. The dimension of self-efficacy for instructional leadership that was most strongly associated with emotional exhaustion and engagement was self-efficacy for motivating teachers. The dimension that was most weakly related to these variables was self-efficacy for creating a positive and safe learning environment for the students.
\end{abstract}

Keywords School principal · Self-efficacy · Instructional leadership · Engagement · Emotional exhaustion

Cecilie Skaalvik

cecilie.skaalvik@ntnu.no

1 Department of Teacher Education, Norwegian University of Science and Technology (NTNU), 7491 Trondheim, Norway 


\section{Introduction}

School principals have a crucial role in developing the learning environment in school, which is important for teacher job satisfaction and student learning. For instance, Butler and Shibaz (2019), in a study of 650 teachers in Israel, found that the principals, through their priorities and evaluations, affect the teachers' goals and practices. However, although the principal functioning may be affected by their working conditions, their level of stress and their mastery expectations, there is little research on school principal stress (Darmody and Smyth 2016) as well as on principal self-efficacy (Federici and Skaalvik 2012). This study explores relations between principal self-efficacy for instructional leadership and principals' experiences of emotional exhaustion, work engagement, and motivation to leave the principal position.

Traditionally, the role of the school principal may be described as one emphasizing bureaucratic and management responsibilities, for instance responsibility for the school economy, facilities, schedules, and personnel (Hallinger et al. 2018). During the last decades, the responsibility of the school principals in many countries has been extended to all aspects of the school management, including student learning, the development of goals and visions, establishing evaluation procedures, and the development of a safe and stimulating learning environment (e.g., Møller and Ottesen 2011; Point et al. 2008). The Norwegian Directorate for Primary and Secondary Education (2016) states that, "By definition, a school leader is responsible for everything that happens within the school" (p. 3), and "The principal is responsible for the pupils' learning outcomes and learning environment and for ensuring good learning processes in the school" (p. 6). This conceptualization of the responsibility of the school principals is a global trend that has led to a stronger focus on instructional leadership and leadership for learning (see Hallinger 2010; Hallinger and Murphy 1985; Liu and Hallinger 2018).

The new leadership role requires a broad range of skills as well as expectations of being able to cope successfully on a number of areas including instructional leadership. The new role may be experienced as challenging and stimulating but also as overwhelming, demanding and exhausting. The present study focuses on principals' self-efficacy for instructional leadership. Because instructional leadership increasingly has been accentuated during the last decades it is important to explore principals' self-efficacy for conducting it and how this aspect of principal self-efficacy relates to engagement and well-being.

Recent research has shown an increasing interest in teacher self-efficacy. The research evidence shows that teacher self-efficacy is positively related to engagement and job satisfaction and negatively related to emotional exhaustion and motivation to leave the teaching profession (Collie et al. 2012; Klassen and Chiu 2011). Less research has been conducted regarding principle self-efficacy. Also, researchers have used different scales assessing different dimensions of principal self-efficacy. Moreover, little attention has been given to self-efficacy for instructional leadership and valid instruments for measuring self-efficacy for instructional leadership as a multidimensional construct is generally lacking. 
One purpose of this study was to develop and factor-analyze a scale for measuring school principals' self-efficacy for instructional leadership. Another purpose was to explore how self-efficacy for instructional leadership was related to emotional exhaustion, engagement, and motivation to leave the position as a school principal.

\section{Theoretical framework}

\subsection{Self-efficacy}

In social cognitive theory self-efficacy is defined as “...peoples judgments of their capabilities to organize and execute courses of action required to attain designated types of performance" (Bandura 1986, p. 391). Thus, self-efficacy refers to a person's future-oriented belief about what he or she is able to do in different areas (Zimmerman and Cleary 2006). The construct is often referred to as "mastery expectations". According to Bong and Skaalvik (2003) self-efficacy may be seen as the answer to questions such as "Can I do it" and "How well can I do it". Self-efficacy is a multidimensional, domain specific construct that varies with the task at hand. People have different mastery expectations for different activities.

According to social cognitive theory self-efficacy affects peoples' cognitions, emotions, and behavior. For instance, research on teachers has shown that self-efficacy is positively related to job satisfaction and engagement and negatively related to burnout and motivation to leave the teaching profession (Brouwers and Tomic 2000; Collie et al. 2012; Skaalvik and Skaalvik 2017a). People with high self-efficacy also tend to set challenging goals for themselves (Bandura 1997) whereas people with low self-efficacy tend to dwell with their shortcomings. People therefore tend to avoid situations and activities for which they have low self-efficacy.

\subsection{Principal self-efficacy}

Tschannen-Moran and Gareis (2004) define principal self-efficacy as a judgment of one's own “... capabilities to structure a particular course of action in order to produce desired outcomes in the school he or she leads (p. 573). This definition covers all responsibilities of the principals. Thus, in accordance with general conceptualizations of the construct, principal self-efficacy is conceptualized as a multidimensional construct.

Although there is a general agreement about how to define principal self-efficacy, there is little agreement as to how to measure the construct. For instance, Dimmock and Hattie (1996) used twelve vignettes to measure self-efficacy in six areas of principal functioning: school development, teaching, learning and curriculum, managing staff, budgeting, managing parents, and managing the environment. Because the vignettes describe particular situations and problems, capturing self-efficacy for each area may require more vignettes than was used by Dimmock and Hattie. Tschannen-Moran and Gareis (2004) tested Hattie's instrument and concluded that is was of insufficient stability and reliability. Tschannen-Moran and Gareis (2004) tested a "Principal Sense of 
Efficacy Scale" (PSES) adapted from the Teacher Self-Efficacy Scale (TSES: Tschannen-Moran and Woolfolk Hoy 2001). An 18-item scale was designed to measure three dimensions of principal self-efficacy with six items each: efficacy for management, efficacy for moral leadership, and efficacy for instructional leadership. Exploratory factor analysis clearly separated the three dimensions and revealed moderate correlations among them. Federici and Skaalvik (2011) tested a 22-item "Norwegian Principal SelfEfficacy Scale" by means of confirmatory factor analyses. A model with eight primary factors and a single second order factor had good fit to the data.

Despite differences in measures of principal self-efficacy the available research indicates that principal self-efficacy is associated with principal well-being and motivation as well as adaptive leadership functioning. Principal self-efficacy has been shown to be positively associated with engagement (Federici and Skaalvik 2011), job satisfaction (Federici and Skaalvik 2012), persistence in pursuing goals (Osterman and Sullivan 1996), motivation for retaining in the principal position (Dimmock and Hattie 1996), the quality of supervision of teachers (Licklider and Niska 1993), collective teacher efficacy (Hallinger et al. 2018), and effort to influence teacher attitudes and behaviors (see Hallinger et al. 2018). Principal self-efficacy has also been shown to be negatively related to burnout and motivation to leave the principal position (Federici and Skaalvik 2012).

\subsection{Self-efficacy for instructional leadership}

Research on self-efficacy for instructional leadership is scarce and there is a lack of valid instruments developed for measuring self-efficacy for instructional leadership as a multidimensional construct. The instructional leadership subscale of the Principal Sense of Efficacy Scale (PSES, Tschannen-Moran and Gareis 2004) had six items focusing on motivating teachers, creating enthusiasm for a shared vision for the school, managing change, facilitate student learning, and raise student achievement. The six items do not capture the variety of functioning related to instructional leadership. For instance, I propose that self-efficacy for observing instruction and providing useful feedback to the teachers is an important dimension of instructional leadership that is not included in the scale. Moreover, I conceptualize self-efficacy for instructional leadership as a multidimensional construct and each dimension of instructional leadership needs to be measured with more than one item. The Norwegian Principal Self-Efficacy Scale (Federici and Skaalvik 2011) also had a subscale measuring self-efficacy for instructional leadership. However, the construct was measured with only two items and do not capture the variety of responsibilities related to instructional leadership. In conclusion, there is a need for a multidimensional scale measuring self-efficacy for instructional leadership that can be used as a separate measure.

\subsubsection{Defining instructional leadership}

In order to develop a scale measuring self-efficacy for instructional leadership it is necessary to analyze the construct of instructional leadership. In an early attempt to define instructional leadership, which was termed instructional management, 
Hallinger and Murphy (1985) discriminated between three dimensions: (a) defining the school mission (e.g., framing and communicating educational goals), (b) managing the instructional program (e.g., supervising and evaluating instruction), and (c) promoting a positive learning climate (e.g., motivating teachers). In a later study Hallinger (2010) used the term "leadership for learning" which he described through three dimensions overlapping the dimensions described in 1985: (a) vision and goals, (b) academic structures and processes, for instance shaping the practice of teachers, and (c) people capacity, for instance supporting the professional learning of the staff.

Robinson (2011) points to some of the same dimensions when describing what she terms "student-centered leadership". According to Robinson, student centered leadership is characterized by five dimensions: (a) clarifying educational goals and expectations, (b) strategic resourcing, (c) planning and evaluating teaching and curriculum, (d) promoting teacher learning, and (e) ensuring an orderly and supportive environment.

Brandmo and Aas (2017) describe the original instructional leadership concept as a top down model of school leadership where the principal is seen as "expert" and "chief". However, the construct of instructional leadership need not have such implications. Ylimaki and Jacobsen (2013) show that contemporary conceptualizations of instructional leadership move away from a strong, directive leadership focused on curriculum and instruction from the principal. Similarly, Osborne-Lampkin et al. (2015) suggest that instructional leadership may be conducted in collaboration with the teachers. Also, Coldren and Spillane (2007) argue that instructional leadership should address both the instructional processes and work to build positive social relations and Mitchell et al. (2015) see the development of a positive and stimulating learning environment as an important aspect of instructional leadership. In this study I use the term "instructional leadership" to refer to a leadership practice that, through initiating reflections on goals and values and influencing the teachers' goals, values, and practices, aim to improve instructional means and methods and to create a positive learning environment. In this conceptualization the aim of instructional leadership is student learning and well-being. Based on previous research (see above) I discriminate between five dimensions of instructional leadership: (a) developing educational goals and visions, (b) creating a collective culture among the staff, (c) motivating teachers, (d) classroom observation and guidance of teachers, and (e) creating a positive and safe learning environment for the students. In my conceptualization, instructional leadership does not require that the principal performs all these tasks personally but they can also be accomplished through delegating some of the tasks.

The development of goals and visions are emphasized as an important aspect of instructional leadership by several researchers (see above). Goals and visions communicate the school's mission or purpose and clarify what should be the focus of attention (Hallinger and Murphy 1985). Creating a collective culture also involves goals and visions. Goals and visions need not only to be developed and communicated, it is also important to work actively with the teachers to create a collective culture in which the teachers internalize common goals and visions. The third dimension is encouraging, motivating and engaging teachers, both to take part in 
the school development, but also for the everyday work with the students. At many schools, teachers claim that the principal or the school leadership are seldom present and that their efforts are not recognized or valued, which appears to be demotivating (Skaalvik and Skaalvik 2015). A core dimension of instructional leadership that directly influences the learning environment is the observation and guidance of teachers. Although there is a need for professional teachers and research shows that teacher job satisfaction is positively correlated with teacher autonomy, observation and guidance of teachers are needed to ensure some degree of common goals and practices. The fifth dimension, creating a positive and safe learning environment for the students, is essential to ensure optimal learning and the well-being of the students.

The five dimensions do not include all previously suggested aspects of instructional or student-centered leadership. Examples of such dimensions are the administration of formal professional learning (Robinson 2011), ensuring that teachers have the time to prepare for teaching (Hallinger and Murphy 1985), and strategic resourcing (Robinson 2011). These are important responsibilities of the school principals; however, they do not directly influence how the instruction is conducted or the visions for the learning environment at school. Also, this study does not focus on how the school principal put the five dimensions into practice. Rather, this study focuses on the principals' beliefs of being able to put the principles underlying the five dimensions of instructional leadership into practice.

\subsubsection{The Norwegian self-efficacy for instructional leadership scale (NSEILS)}

The NSEILS was developed to measure self-efficacy for developing educational goals and visions, creating a collective culture among the staff, motivating teachers, classroom observation and guidance of teachers, and creating a positive and safe learning environment for the students (see Sect. 3.2).

\subsection{Emotional exhaustion}

Emotional exhaustion is characterized by low energy and chronic fatigue (Pines and Aronson 1988; Schwarzer et al. 2000). It is a central dimension of burnout and results from long-term work-related stress (Jennett et al. 2003). Burnout is commonly conceptualized as a syndrome consisting of emotional exhaustion, depersonalization, and low personal accomplishment (Maslach et al. 1996).

Research on teachers indicates that emotional exhaustion is predicted by low self-efficacy (Brouwers and Tomic 2000; Evers et al. 2002; Friedman and Farber 1992; Saricam and Sakiz 2014) but also by stressful working conditions (Betoret and Artiga 2010; Fernet et al. 2012; Skaalvik and Skaalvik 2017b). Burnout among teachers has also been shown to be predictive of low job satisfaction and intentions of leaving the profession (Leung and Lee 2006; Skaalvik and Skaalvik 2010). I therefore expected that emotional exhaustion among school principals would be negatively predicted by self-efficacy for instructional leadership. I also expected that 
emotional exhaustion would be predictive of lower levels of engagement and higher motivation to leave to principal position.

\subsection{Engagement}

Work engagement is often defined as "... a positive, fulfilling work-related state of mind that is characterized by vigor, dedication, and absorption" (e.g., Bakker et al. 2011 , p. 5). Thus, work engagement is a motivational construct which is positively related to effort and job performance (Bakker and Bal 2010; Demerouti and Cropanzano 2010). In a study of Finnish teachers, Hakanen et al. (2006) also found that engagement was positively associated with organizational commitment. Consequently, it is reasonable to expect that engaged principals are more motivated to continue working as school leaders. Demerouti et al. (2001) also found that work engagement was negatively related to health problems like psychosomatic symptoms. However, research evidence generally fails to find strong relations between engagement and physiological indicators of health (Bakker et al. 2011). Previous research also reveals a positive association between work engagement and self-efficacy (Halbesleben 2010; Sweetman and Luthans 2010). I expected engagement to be positively related to self-efficacy for instructional leadership.

\subsection{The present study}

One purpose of the present study was to develop a scale for measuring self-efficacy for instructional leadership containing the five dimensions discussed above (see Sect. 2.3). The factor structure of the proposed scale was tested by means for confirmatory factor analyses defining five factors. I also tested if a model with selfefficacy represented by a second order factor fitted the data.

Another purpose was to explore how principal self-efficacy for instructional leadership was related to emotional exhaustion, engagement, and motivation to leave the position as a school principal. According to social cognitive theory, self-efficacy is an important predictor of vulnerability to burnout (Bandura 1997). Bandura explains that people with low self-efficacy resort to escapist modes of coping that only create more strain and distress. Moreover, as explained in the introduction, the Norwegian Directorate of Primary and Secondary Education (2015) underscores that the principal is responsible for everything that happens within the school, including student learning. I therefore expected that self-efficacy for instructional leadership would be negatively related to emotional exhaustion and positively related to engagement. I also expected that self-efficacy would, both directly and indirectly, be related to engagement and that the indirect relation would be mediated through emotional exhaustion. Another expectation was that principals with high self-efficacy would be less motivated to leave the position as a principal and that this relation in part would be mediated through emotional exhaustion and engagement. A theoretical model was developed based on these expectations (Fig. 1). 


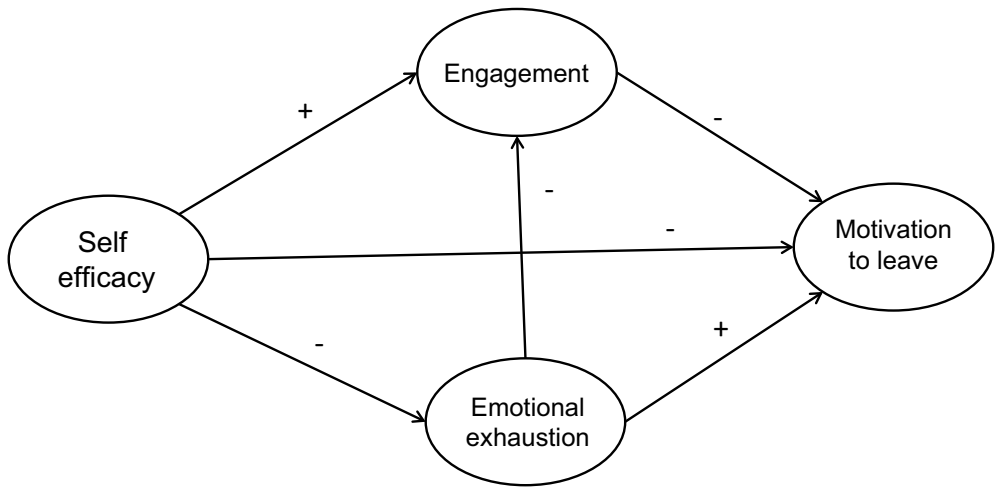

Fig. 1 Theoretical model of relations between the study variables

\section{Method}

\subsection{Participants and procedure}

Participants in this study were 340 principals in elementary school and high school in five randomly selected counties in Norway. Data were collected using an electronic questionnaire. The sample consisted of 58.9\% female principals and $41.1 \%$ male principals. Six percent of the participants were between 30 and 40 years of age, $39 \%$ were between 41 and 50, 35\% were between 51 and 60, and $20 \%$ were past 60 years of age. The number of teachers at the schools varied from 10 to 90 with a mean of 26. Forty-five percent of the principals were working in cities whereas $55 \%$ were working in schools in rural areas.

\subsection{Instrument}

\subsubsection{Self-efficacy for instructional leadership}

Self-efficacy for instructional leadership was measured by means of a 15-item Norwegian self-efficacy for instructional leadership scale (NSEILS) consisting of five subscales: (a) development of goals and visions for the school, (b) development of a collective culture, (c) motivating teachers, (d) classroom observation and guidance of teachers, and (e) creating a positive and safe learning environment for the students. Examples of items are: "How certain are you that you can create engagement among the teachers?" (self-efficacy for motivating teachers) and "How certain are you that you can develop a culture were all teachers work towards the same goals and values?" (self-efficacy for creating a collective culture). Responses were given on a 7-point scale from "Not certain at all" (1) to "Absolutely certain" (7). The scale is displayed in "Appendix". Cronbach's alpha for the total scale was .88. Alphas for the subscales were $.90, .84, .72, .76$, and .82 for goals, collective culture, motivating teachers, observing and guiding instruction, and learning environment, respectively. 


\subsubsection{Emotional exhaustion}

Emotional exhaustion was measured by a six-item scale focusing on lacking energy and feeling tired from the work as a principal. Examples of items are: "I feel exhausted from working as a principal" and "Working as a principal takes all my energy." Responses were given on a 6-point scale from "Strongly disagree" (1) to "Strongly agree" (6). Cronbach's alpha for the scale was .91.

\subsubsection{Engagement}

Engagement was measured by means of the nine-item version of the Utrecht Work Engagement Scale (Scaufeli et al. 2006). An example of an item is: "At my work, I feel bursting with energy". Responses were given on a 7-point scale from "Never" (1) to "Every day" (7). Cronbach's alpha for the scale was .89.

\subsubsection{Motivation to leave to the principal position}

Motivation to leave the position as a principal was measured by a modified three item scale originally developed for teacher research (Skaalvik and Skaalvik 2011). An example of an item is: "I often think of leaving the position as a principal." Responses were given on a 6-point scale from "Strongly disagree" (1) to "Strongly agree" (6). Cronbach's alpha for the scale was .92 .

\subsection{Data analysis}

The data were analyzed by means of confirmatory factor analyses and structural equation modeling (SEM) using the AMOS 25 program. I first tested two measurement models of instructional leadership, one model defining five correlated primary factors and one model defining a single second order factor indicated by the primary factors. Secondly, I tested a structural model exploring associations between a second order self-efficacy for instructional leadership variable, emotional exhaustion, engagement, and motivation to leave the position as a principal. The theoretical model is displayed in Fig. 1. Thirdly, I estimated associations between the five primary self-efficacy factors and emotional exhaustion, engagement and motivation to leave the position as a principal. Associations between latent variables were estimated by means of confirmatory factor analysis. Model fit was indicated by well-established indices such as RMSEA, CFI, IFI, and TLI. For well-specified models, an RMSEA of .06 or less reflects a good fit (Hu and Bentler 1999). For the CFI, IFI, and TLI indices, values greater than .90 are typically considered acceptable and values greater than .95 indicate a good fit to the data (Bollen 1989; Byrne 2001; Hu and Bentler 1999). 
Table 1 Standardized regression coefficients in measurement Model 1

\begin{tabular}{lllll}
\hline Develop goals & $\begin{array}{l}\text { Collective } \\
\text { culture }\end{array}$ & $\begin{array}{l}\text { Motivating } \\
\text { teachers }\end{array}$ & $\begin{array}{l}\text { Guiding } \\
\text { teachers }\end{array}$ & $\begin{array}{l}\text { Learning } \\
\text { environ- } \\
\text { ment }\end{array}$ \\
\end{tabular}

.92

.90

.83

.80

.80

.78

.75

.69

.67

Table 2 Correlations among the primary self-efficacy factors

\begin{tabular}{llllll}
\hline & 1 & 2 & 3 & 4 & 5 \\
\hline 1. Develop goals & - & .62 & .69 & .65 & .41 \\
2. Develop a collective culture & & - & .85 & .56 & .60 \\
3. Motivate teachers & & & - & .61 & .62 \\
4. Observe and guide teachers & & & & - & .38 \\
5. Develop a positive environment & & & & - \\
\hline
\end{tabular}

\section{Results}

\subsection{Confirmatory factor analyses: testing measurement models of the NSEILS}

I first tested a measurement model defining five correlated primary factors: selfefficacy for (a) developing goals and visions for the school, (b) developing a collective culture, (c) motivating teachers, (d) conducting classroom observation and guiding teachers, and (e) creating a positive and safe learning environment for the students. Each of these factors were indicated by three items (see "Appendix"). The model had good fit to the data $\left(\chi^{2}[81, N=340]=191.726, p<.001\right.$, RMSEA $=.064$, $\mathrm{IFI}=.956, \mathrm{CFI}=.955, \mathrm{TLI}=.934$ ). All of the 15 factor loadings (standardized regression weights) were strong and ranged from .67 to .93 (Table 1). The correlations between the five primary factors ranged from .38 to .85 (Table 2). Seven of the correlations were between .60 and .85 . Self-efficacy for motivating teachers correlated particularly strongly with self-efficacy for developing a collective culture (.85). 
Table 3 Descriptive statistics for the self-efficacy for instructional leadership scale (NSEILS)

\begin{tabular}{lcclll}
\hline & Mean & $S D$ & Minimum & Maximum & Alpha \\
\hline Develop goals & 5.39 & .85 & 1.33 & 7.00 & .90 \\
Collective culture & 5.19 & .68 & 3.00 & 7.00 & .84 \\
Motivate teachers & 5.12 & .64 & 2.67 & 7.00 & .72 \\
Guiding teachers & 5.03 & .89 & 2.00 & 7.00 & .76 \\
Learning environment & 5.36 & .69 & 3.33 & 7.00 & .82 \\
Total scale & 5.22 & .58 & 3.07 & 7.00 & .94 \\
\hline
\end{tabular}

On the other hand, self-efficacy for creating a positive and safe learning environment for the students correlated moderately both with self-efficacy for guiding teachers (.38) and with self-efficacy for developing goals (.41).

The second measurement model defined a second order factor representing a general self-efficacy for instructional leadership. The model had good fit to the data $\left(\chi^{2}[86, N=340]=228.515, p<.001, \mathrm{RMSEA}=.070, \mathrm{IFI}=.943, \mathrm{CFI}=.942\right.$, $\mathrm{TLI}=.920)$. All the five primary factors loaded strongly on the second order factor: $.78, .86, .93, .69$, and .63 for developing goals and visions for the school, developing a collective culture, motivating teachers, conducting classroom observation and guiding teachers, and creating a positive and safe learning environment for the students, respectively.

The two models were compared using the $\mathrm{Chi}^{2}$-difference test $\left(\Delta \mathrm{Chi}^{2}\right)$ and difference in CFI $(\Delta \mathrm{CFI})$. An absolute difference in CFI that is higher than 0.01 would indicate a significant difference in model fit. The $\mathrm{Chi}^{2}$-difference test indicated that a model with primary factors fits the data significantly better than a model with a second order self-efficacy factor $\left(\Delta \mathrm{Chi}^{2}=36.79, \Delta \mathrm{df}=5\right)$, whereas $\Delta \mathrm{CFI}$ did not exceed one $(\Delta \mathrm{CFI}=0.01)$. More importantly, the testing of the measurement models showed that both a second order model and a model with primary factors had good fit to the data and that both models are adequate for subsequent analysis. However, some of the correlations between the primary factors are very strong (see Table 2). Therefore, because of a possible collinearity problem, I conducted a SEM analysis in which self-efficacy for instructional leadership was represented by a second order factor whereas relations between dimensions of self-efficacy and emotional exhaustion, engagement, and motivation to leave the principal position were estimated as correlations between the latent variables in a confirmatory factor analysis (see Sect. 4.3).

\subsection{Descriptive statistics}

Table 3 shows descriptive statistics for the self-efficacy scale. The total scale had a statistical mean of 5.22 and the subscales had means ranging from 5.03 to 5.39. Thus, the statistical means for all subscales were on the positive side of the response scale. Reliabilities in terms of Cronbach's alpha were good and ranged from .72 to .94 . 


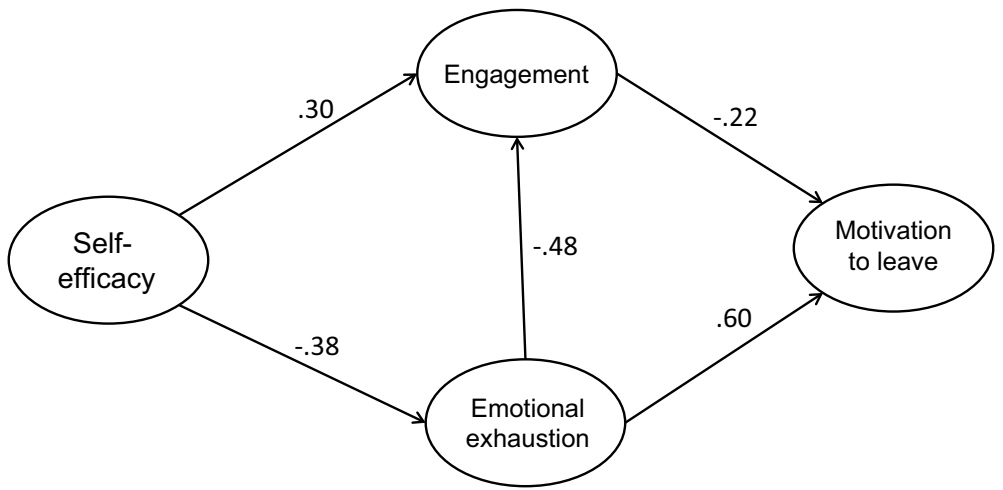

Fig. 2 Structural model of relations between self-efficacy for instructional leadership, emotional exhaustion, engagement, and motivation to leave the principal position. Standardized regression coefficients are reported

\subsection{Relations between self-efficacy and emotional exhaustion, engagement, and motivation to leave to principal position}

The next step in the data analyses was to test how self-efficacy for instructional leadership related to emotional exhaustion, engagement, and motivation to leave the principal position. The relations were explored partly by means of structural equation modelling (SEM analysis) and partly by means of confirmatory factor analysis exploring correlations between latent variables.

\subsubsection{SEM analysis}

I first tested the theoretical model (Fig. 1) of relations between self-efficacy for instructional leadership, emotional exhaustion, engagement, and motivation to leave to principal position. In this model self-efficacy was represented by a single second order factor. The empirical model is displayed in Fig. 2 and reports standardized regression weights. The model had acceptable fit to the data $\left(\chi^{2}[425\right.$, $N=340]=857.128, p<.001, \mathrm{RMSEA}=.055, \mathrm{IFI}=.930, \mathrm{CFI}=.929, \mathrm{TLI}=.917)$. As expected, self-efficacy for instructional leadership was negatively related to emotional exhaustion (beta $=-.38$ ) and positively related to engagement (beta $=.30$ ). Moreover, emotional exhaustion was negatively related to engagement (beta $=-.48$ ). Thus, in the SEM model, self-efficacy for instructional leadership was both directly and indirectly related to engagement. The total effect of self-efficacy on engagement was .47 .

Self-efficacy for instructional leadership was in the model not directly related to motivation to leave principal position. However, it was indirectly related to motivation to leave, both through emotional exhaustion and engagement. Emotional exhaustion was positively associated with motivation to leave (beta $=.60$ ) whereas engagement was negatively associated with motivation to leave (beta $=-.22$ ). The 
Table 4 Correlations between the primary self-efficacy factors and emotional exhaustion, engagement, and motivation to leave the principal position

\begin{tabular}{llll}
\hline Dimensions of self-efficacy & 1 & 2 & 3 \\
& $\begin{array}{l}\text { Emotional } \\
\text { exhaustion }\end{array}$ & Engagement & Quit \\
\hline 1. Motivate teachers & -.42 & .48 & -.40 \\
2. Collective culture & -.24 & .38 & -.24 \\
3. Develop goals & -.28 & .40 & -.26 \\
4. Guiding teachers & -.22 & .29 & -.29 \\
5. Learning environment & -.17 & .22 & -.23 \\
\hline
\end{tabular}

All correlations are between latent variables

indirect effect of self-efficacy for instructional leadership on motivation to leave was -.33 .

\subsubsection{Correlations between dimensions of self-efficacy for instructional leadership and engagement, emotional exhaustion, and motivation to leave}

I then analyzed how each of the self-efficacy dimensions were associated with emotional exhaustion, engagement, and motivation to leave the principal position. Structural equation modeling (SEM) would be the preferred procedure for this purpose. However, the strong correlations between the self-efficacy dimensions (see Table 2) indicate that SEM analysis would suffer from collinearity problems. I therefore conducted a confirmatory factor analysis defining five primary self-efficacy factors, emotional exhaustion, engagement, and motivation to leave the principal position. The model had good fit to the data $\left(\chi^{2}[407, N=340]=793.962, p<.001\right.$, $\mathrm{RMSEA}=.053, \mathrm{IFI}=.938, \mathrm{CFI}=.937, \mathrm{TLI}=.923)$.

The correlations between the five latent self-efficacy factors and emotional exhaustion, engagement, and motivation to leave the principal position are reported in Table 4. The strongest correlations with the outcome variables were systematically found for self-efficacy for motivating teachers $(-.42, .48$, and -.40 with emotional exhaustion, engagement, and motivation to leave the principal position, respectively). In comparison, the weakest correlations were found for self-efficacy for creating a positive and safe learning environment for the students $(-.17, .22$, and -.23 with emotional exhaustion, engagement, and motivation to leave the principal position, respectively).

\section{Discussion}

One purpose of this study was to develop and test a new 15-item scale for measuring self-efficacy for instructional leadership. The scale was designed to measure five dimensions of self-efficacy for instructional leadership with three items each. The dimensions were: self-efficacy for developing goals and visions for the school, developing a collective culture, motivating teachers, conducting classroom 
observation and guiding teachers, and creating a positive and safe learning environment for the students.

Confirmatory factor analyses revealed that both a model with five correlated primary factors and a model with a single second order factor had good fit to the data and that all factor loadings were strong. Cronbach's alphas also revealed high internal consistency, both for the total scale and for the five subscales. Even though the $\mathrm{Chi}^{2}$-difference test indicated that the model with primary factors had the best fit to the data, the results showed that both models would be adequate for analysis of relations between principals' self-efficacy for instructional leadership and possible outcomes as well as antecedents of self-efficacy. Because both measurement models had good fit to the data, researchers may choose to use either a model with primary factors or a model with a second order factor dependent on the research questions.

A SEM analysis in which self-efficacy was represented by a second order factor showed that self-efficacy for instructional leadership was associated with emotional exhaustion, engagement, and motivation to leave the principal position. Self-efficacy for instructional leadership was predictive of lower levels of exhaustion, higher levels of engagement, and lower motivation to leave the position. These results are in accordance with theoretical expectations and therefore indicate good criterion validity of the scale. However, it is important to note that, in the SEM model, selfefficacy was not directly related to the principals' motivation to leave the position. The relation was indirect and mediated through emotional exhaustion and engagement. A possible interpretation is that high self-efficacy for instructional leadership may result in lower levels of emotional exhaustion and higher levels of engagement which in turn increases the motivation to stay in the principal position. Low selfefficacy may, on the other hand, result in higher levels of emotional exhaustion and lower levels of engagement which in turn increases the motivation to leave the position. This interpretation highlights the importance of designing the principal role in order to increase engagement and to avoid emotional exhaustion.

An assumption in social cognitive theory is that people are motivated to avoid situations and activities for which they have low mastery expectations. The lack of a direct link between self-efficacy and motivation to leave the principal position does not contradict this assumption. Avoiding instructional leadership does not require that one leave the position as a principal, but may also be achieved through prioritizing other management responsibilities. This interpretation cannot be tested based on the present data and needs to be addressed in future research. However, as discussed above, the association between self-efficacy for instructional leadership and motivation to leave appears to be mediated through emotional exhaustion and engagement. This finding is in accordance with social cognitive theory and extends the theory rather that contradicting it.

A possible interpretation of the associations between self-efficacy for instructional leadership and both emotional exhaustion and engagement is that even principals with low self-efficacy are trying to conduct instructional leadership, but with low mastery experiences and without feeling comfortable with this undertaking. This interpretation would explain both that low self-efficacy predicts an increase of emotional exhaustion and a decrease of engagement. The interpretation is also in accordance with the lack of a direct association between 
self-efficacy and motivation to leave the principal position. An alternative interpretation may be that principals with low self-efficacy for instructional leadership actually are avoiding this dimension of school leadership. However, principals who are avoiding instructional leadership may also feel uncomfortable and unsuccessful, because they are avoiding a responsibility that they are clearly expected to undertake. Both these explanations highlight the need for a principal education with strong emphasis on the value of instructional leadership as well as the skills and competences that such a leadership requires.

The dimension of self-efficacy that was most strongly related to all outcome variables in this study, was self-efficacy for motivating teachers (see Table 4). A possible interpretation of this finding is that the quality of the education is dependent on teacher motivation. The expectation of not being able to motivate the teachers may therefore be a major source of stress and exhaustion among school principals whereas expectations of being able to motivate the teachers may be an important source of principal engagement.

The dimension of self-efficacy for instructional leadership that was most weakly related to the outcome variables was self-efficacy for creating a positive and safe learning environment for the students. For instance, self-efficacy for creating a positive and safe learning environment correlated only -.17 with emotional exhaustion (see Table 4). Consequently, in the present sample, the expectation of not being able to create a positive and safe learning environment for the students does not seem to bother the principals very much. Also, the expectation of being able to create a positive learning environment seems to have little impact on the principals' work engagement. This interpretation needs to be verified in future research, because it implies that, for many principals, creating a positive and safe learning environment for the students is not perceived as a core aspect of the principal responsibility. This interpretation is supported by the finding that self-efficacy for creating a positive and safe learning environment for the students correlated weakly both with self-efficacy for guiding teachers (.38) and with self-efficacy for developing goals (.41), which may indicate that creating a positive and safe learning environment for the students are not salient for many of the principals when developing goals and guiding teachers. If so, this finding is quite disturbing and needs to be addressed in principal education.

This study has several limitations and the findings and interpretations need to be verified in future research. The study was designed as a cross sectional study and one should be careful not to draw firm causal interpretations. There is a need for longitudinal studies. Also, the study is based on a Norwegian sample, and needs to be replicated in other cultures. Only three possible outcome variables were included in this study: emotional exhaustion, engagement, and motivation to leave the principal position. Future studies should also include more outcome variables. Furthermore, there is a need for qualitative studies to explore principals' prioritizations of leadership responsibilities as well as their self-perceived reasons for the prioritizations. 


\section{Conclusions}

Although instructional leadership has gained much attention in educational research the last couple of decades, little research has focused on self-efficacy for instructional leadership. Moreover, there has been a lack of valid instruments for measuring this aspect of principal self-efficacy. The Norwegian self-efficacy for instructional leadership scale appears as a reliable and valid scale which may be used both as a single measure of self-efficacy for instructional leadership or as a measure of its dimensions. This study also shows that self-efficacy for instructional leadership is predictive of principals' well-being (emotional exhaustion), motivation (in this study measured both as engagement and as motivation to continue or to leave the principal position.

Acknowledgements Open Access funding provided by NTNU Norwegian University of Science and Technology (incl St. Olavs Hospital - Trondheim University Hospital). This research was supported by a grant from the Norwegian University of Science and Technology.

\section{Compliance with ethical standards}

Conflict of interest The author declares that she have no conflict of interest.

Ethical approval The study was conducted in line with the ethical research guidelines and approved by the Norwegian Centre for Research Data (NSD) which serves as a national ethical research committee.

Open Access This article is licensed under a Creative Commons Attribution 4.0 International License, which permits use, sharing, adaptation, distribution and reproduction in any medium or format, as long as you give appropriate credit to the original author(s) and the source, provide a link to the Creative Commons licence, and indicate if changes were made. The images or other third party material in this article are included in the article's Creative Commons licence, unless indicated otherwise in a credit line to the material. If material is not included in the article's Creative Commons licence and your intended use is not permitted by statutory regulation or exceeds the permitted use, you will need to obtain permission directly from the copyright holder. To view a copy of this licence, visit http://creativecommons.org/licen ses/by/4.0/.

\section{Appendix}

\section{The Norwegian principal self-efficacy for instructional leadership scale ${ }^{1}$}

How certain are you that you can:

\section{Develop goals}

1. Develop clear and achievable goals for the school

2. Develop clear goals and expectations for the teaching

3. Develop a strategic plan for achieving the goals

\footnotetext{
${ }^{1}$ The scale represents a translation from the original Norwegian scale.
} 


\section{Guide teachers}

4. Guide teachers about educational matters

5. Observe teaching and provide helpful feedback

6. Use school based self-assessment to improve teaching and learning

\section{Create a positive and safe learning environment}

7. Promote a safe school environment for students which is free from bullying

8. Ensure a learning environment in which students feel safe

9. Promote a good teacher-student relationship

\section{Motivate teachers}

10. Create enthusiasm and engagement among the teachers

11. Motivate the teachers for teaching and instruction

12. Motivate the teachers to commit to the goals

\section{Develop a collective culture}

13. Develop a collective culture in which everyone works to achieve shared goals

14. Develop a culture in which teachers support each other

15. Promote a shared understanding of what constitutes good teaching

\section{Response categories}

(1) Not certain at all, (3) Quite uncertain, (5) Quite certain, (7) Absolutely certain.

\section{References}

Bakker, A. B., Albrecht, S. L., \& Leiter, M. P. (2011). Key questions regarding work engagement. European Journal of Work and Organizational Psychology, 20, 4-28. https://doi.org/10.1080/13594 32X.2010.485352.

Bakker, A. B., \& Bal, P. M. (2010). Weekly work engagement and performance: A study among starting teachers. Journal of Occupational and Organizational Psychology, 83, 189-206. https://doi. org/10.1348/096317909x402596.

Bandura, A. (1986). Social foundations of thought and action. Englewood Cliffs, NJ: Prentice-Hall.

Bandura, A. (1997). Self-efficacy: The exercise of control. New York: Freeman.

Betoret, F. D., \& Artiga, A. G. (2010). Barriers perceived by teachers at work, coping strategies, self-efficacy and burnout. The Spanish Journal of Psychology, 13, 637-654. https://doi.org/10.1017/s1138 741600002316.

Bollen, K. A. (1989). A new incremental fit index for general structural models. Sociological Methods and Research, 17, 303-316. https://doi.org/10.1177/0049124189017003004.

Bong, M., \& Skaalvik, E. M. (2003). Academic self-concept and self-efficacy: How different are they really? Educational Psychology Review, 15, 1-40. https://doi.org/10.1023/a:1021302408382. 
Brandmo, C., \& Aas, M. (2017). Med skråblikk på ledelsesmodeller: "Instructional” og "transformational» ledelse i norsk kontekst [With an oblique look at management models: Instructional and transformational leadership in a Norwegian context]. In M. Aas \& M. Paulsen (Eds.), Ledelse $i$ framtidens skole [Leadership in the school of the future] (pp. 53-72). Bergen: Fagbokforlaget.

Brouwers, A., \& Tomic, W. (2000). A longitudinal study of teacher burnout and perceived self-efficacy in classroom management. Teaching and Teacher Education, 16, 239-253. https://doi.org/10.1016/ s0742-051x(99)00057-8.

Butler, R., \& Shibaz, L. (2019). For worse more than better. School principal influences on teachers' achievement goals and instruction. Symposium paper presented at the EARLI conference in Aachen in August 2019.

Byrne, B. M. (2001). Structural equation modelling with AMOS. Basic concepts, applications, and programming. Mahwah, NJ: Lawrence Erlbaum Ass.

Coldren, A. F., \& Spillane, J. P. (2007). Making connections to teaching practice: The role of boundary practices in instructional leadership. Educational Policy, 21, 369-396.

Collie, R. J., Shapka, J. D., \& Perry, N. E. (2012). School climate and social-emotional learning: Predicting teacher stress, job satisfaction, and teaching efficacy. Journal of Educational Psychology, 104, 1189-1204. https://doi.org/10.1037/a0029356.

Darmody, M., \& Smyth, E. (2016). Primary school principals' job satisfaction and occupational stress. International Journal of Educational Management, 30, 115-128. https://doi.org/10.1108/ ijem-12-2014-0162.

Demerouti, E., Bakker, A. B., de Jonge, J., Janssen, P. P. M., \& Schaufeli, W. B. (2001). Burnout and engagement at work as a function of demands and control. Scandinavian Journal of Work, Environment and Health, 27, 279-286.

Demerouti, E., \& Cropanzano, R. (2010). From thought to action: Employee work engagement and performance. In A. B. Bakker \& M. P. Leiter (Eds.), Work engagement: A handbook of essential theory and research (pp. 147-163). New York: Psychology Press.

Dimmock, C., \& Hattie, J. (1996). School principals' self-efficacy and its measurement in the context of restructuring. School Effictiveness and School Improvement, 7(1), 62-75. https://doi. org/10.1080/0924345960070103.

Evers, W. J. G., Brouwers, A., \& Tomic, W. (2002). Burnout and self-efficacy: A study on teachers' beliefs when implementing an innovative educational system in the Netherlands. British Journal of Educational Psychology, 72, 227-243. https://doi.org/10.1348/000709902158865.

Federici, R. A., \& Skaalvik, E. M. (2011). Principal self-efficacy and work engagement: Assessing a Norwegian Principal Self-Efficacy Scale. Social Psychology of Education, 14, 1-26. https://doi. org/10.1007/s11218-011-9160-4.

Federici, R. A., \& Skaalvik, E. M. (2012). Principal self-efficacy: Relations with burnout, job satisfaction and motivation to quit. Social Psychology of Education, 15, 295-320. https://doi.org/10.1007/s1121 8-012-9183-5.

Fernet, C., Guay, F., Senécal, C., \& Austin, S. (2012). Predicting intraindividual changes in teacher burnout: The role of perceived school environment and motivational factors. Teaching and Teacher Education, 28, 514-525. https://doi.org/10.1016/j.tate.2011.11.013.

Friedman, I. A., \& Farber, B. A. (1992). Professional self-concept as a predictor of teacher burnout. Journal of Educational Research, 86, 28-35. https://doi.org/10.1080/00220671.1992.9941824.

Hakanen, J. J., Bakker, A. B., \& Schaufeli, W. B. (2006). Burnout and work engagement among teachers. Journal of School Psychology, 43, 495-513. https://doi.org/10.1016/j.jsp.2005.11.001.

Halbesleben, J. R. B. (2010). A meta-analysis of work engagement: Relationships with burnout, demands, resources, and consequences. In A. Bakker \& M. P. Leiter (Eds.), Work engagement: A handbook of essential theory and research (pp. 102-107). Hove and New York: Psychology Press.

Hallinger, P. (2010). Leadership for learning: Lessons from 40 years of empirical research. Journal of Educational Administration, 49, 125-142. https://doi.org/10.1108/09578231111116699.

Hallinger, P., Hosseingholizadeh, R., Hashemi, N., \& Kouhsari, M. (2018). Do beliefs make a difference? Exploring how principal self-efficacy and instructional leadership impact teacher efficacy and commitment in Iran. Educational Management Administration and Leadership, 46, 800-819. https://doi. org/10.1177/1741143217700283.

Hallinger, P., \& Murphy, J. (1985). Assessing the instructional management behavior of principals. The Elementary School Journal, 86, 217-247. https://doi.org/10.1086/461445. 
Hu, L. T., \& Bentler, P. M. (1999). Cutoff criteria for fit indexes in covariance structure analysis: Conventional criteria versus new alternatives. Structural Equation Modeling: A Multidisciplinary Journal, 6, 1-55. https://doi.org/10.1080/10705519909540118.

Jennett, H. K., Harris, S. L., \& Mesibov, G. B. (2003). Commitment to philosophy, teacher efficacy, and burnout among teachers of children with autism. Journal of Autism and Developmental Disorders, 33, 583-593. https://doi.org/10.1023/b:jadd.0000005996.19417.57.

Klassen, R., \& Chiu, M. M. (2011). The occupational commitment and intention to quit of practicing and pre-service teachers: Influence of self-efficacy, job stress, and teaching context. Contemporary Educational Psychology, 36, 114-129. https://doi.org/10.1016/j.cedpsych.2011.01.002.

Leung, D. Y. P., \& Lee, W. W. S. (2006). Predicting intention to quit among Chinese teachers: Differential predictability of the components of burnout. Anxity Stress and Coping. An International Journal, 19, 129-141. https://doi.org/10.1080/10615800600565476.

Licklider, B. L., \& Niska, J. M. (1993). Improving supervision of cooperative learning: A new approach to staff development for principals. Journal of Personel Evaluation in Education, 6, 367-378.

Liu, S., \& Hallinger, P. (2018). Principal instructional leadership, teacher self-efficacy, and teacher professional learning in China: Testing a mediated-effects model. Educational Administration Quarterly, 54, 501-528. https://doi.org/10.1177/001316x18769048.

Maslach, C., Jackson, S. E., \& Leiter, M. P. (1996). Maslach burnout inventory manual (3rd ed.). Mountain View, CA: CPP Inc.

Mitchell, R., Kensler, L. A. W., \& Tschannen-Moran, M. (2015). Examining the effects of instructional leadership on student academic press and student achievement. Journal of School Leadership, 25, $223-251$.

Møller, J., \& Ottesen, E. (2011). Styring, ledelse og kunnskapsutvikling i skolen [Governance, leadership and knowledge development in the school]. In J. Møller \& E. Ottesen (Eds.), Rektor som leder og sjef [The principal as leader and manager] (pp. 15-26). Oslo: Universitetsforlaget.

Osborne-Lampkin, L., Folsom, J. S., \& Herrington, C. D. (2015). A systematic review of the relationships between principal characteristics and student achievement. Florida: Florida Center for Reading Research, Florida State University.

Osterman, K., \& Sullivan, S. (1996). New principals in an urban bureaucracy: A sense of efficacy. Journal of School Leadership, 6, 661-690.

Pines, A., \& Aronson, E. (1988). Career burnout. Causes and cures. New York: The Free Press.

Point, B., Nusche, D., \& Moorman, H. (2008). Improving school leadership policy and practice. Preliminary version. Paris: Education and Training Policy Division, OECD.

Robinson, V. (2011). Student-centered leadership. San Fransisco: Wiley.

Saricam, H., \& Sakiz, H. (2014). Burnout and teachers' self-efficacy among teachers working in special education in Turkey. Educational Studies, 40, 423-437. https://doi.org/10.1037/0022-0663.90.3.528.

Scaufeli, W. B., Bakker, A. B., \& Salaniva, N. (2006). The measurement of work-engagement with a short questionnaire: A cross-national study. Educational and Psychological Measurement, 66, 701716. https://doi.org/10.1177/0013164405282471.

Schwarzer, R., Schmitz, G. S., \& Tang, C. (2000). Teacher burnout in Hong Kong and Germany: A crosscultural validation of the Maslach Burnout Inventory. Anxiety Stress and Coping, 13, 309-323. https ://doi.org/10.1080/10615800008549268.

Skaalvik, E. M., \& Skaalvik, S. (2010). Teacher self-efficacy and teacher burnout: A study of relations. Teaching and Teacher Education, 26, 1059-1069. https://doi.org/10.1016/j.tate.2009.11.001.

Skaalvik, E. M., \& Skaalvik, S. (2011). Teacher job satisfaction and motivation to leave the teaching profession: Relations with school context, feeling of belonging, and emotional exhaustion. Teaching and Teacher Education, 27, 1029-1038. https://doi.org/10.1016/j.tate.2011.04.001.

Skaalvik, E. M., \& Skaalvik, S. (2015). Job satisfaction, stress and coping strategies in the teaching profession: What do teachers say? International Education Studies, 8, 181-192. https://doi. org/10.2466/14.02.pr0.114k14w0.

Skaalvik, E. M., \& Skaalvik, S. (2017a). Motivated for teaching? Associations with school goal structure, teacher self-efficacy, job satisfaction and emotional exhaustion. Teaching and Teacher Education, 67, 152-160. https://doi.org/10.1016/j.tate.2017.06.006.

Skaalvik, E. M., \& Skaalvik, S. (2017b). Dimensions of teacher burnout: Relations with potential stressors at school. Social Psychology of Education, 20, 775-790. https://doi.org/10.1007/s1121 8-017-9391-0. 
Sweetman, D., \& Luthans, F. (2010). The power of positive psychology: Psychological captital and work engagement. In A. B. Bakker \& M. P. Leiter (Eds.), Work engagement: A handbook of essential theory and research (pp. 54-68). New York: Psychology Press.

The Norwegian Directorate for Primary and Secondary Education. (2016). Leadership in schools. What is required and expected of a school principal. https://www.udir.no/kvalitet-og-kompetanse/etter-ogvidereutdanning/rektor/krav-og-forventninger-til-en-rektor/.

Tschannen-Moran, M., \& Gareis, C. R. (2004). Principals' sense of efficacy: Assessing a promising construct. Journal of Educational Administration, 42(5), 573-585. https://doi.org/10.1108/0957823041 0554070 .

Tschannen-Moran, M., \& Woolfolk Hoy, A. (2001). Teacher efficacy: Capturing and elusive construct. Teaching and Teacher Education, 17, 783-805. https://doi.org/10.1016/s0742-051x(01)00036-1.

Ylimaki, R., \& Jacobsen, S. (2013). School leadership practice and preparation: Comparative perspectives on organizational learning (OL), instructional leadership (IL), and culturally responsive practices (CRP). Journal of Educational Administration, 51, 6-23. https://doi.org/10.1108/0957823131 1291404.

Zimmerman, B. J., \& Cleary, T. J. (2006). Adolescents' development of personal agency: The role of self-efficacy beliefs and self-regulatory skills. In F. Pajares \& T. Urdan (Eds.), Self-efficacy beliefs of adolecents (pp. 45-69). Greenwich: Information Age.

Publisher's Note Springer Nature remains neutral with regard to jurisdictional claims in published maps and institutional affiliations.

Cecilie Skaalvik is an Assistant Professor at the Department of Teacher Education at the Norwegian University of Science and Technology. Her research interests are in the areas of school leadership, special education, motivation, self-efficacy, and self-concept. 